\title{
PENERAPAN SUPPORT VECTOR MACHINE (SVM) PADA SMALL DATASET UNTUK DETEKSI DINI GANGGUAN AUTISME
}

\author{
Bayu Sugara'; Agus Subekti² \\ 1,2Program Studi Magister Ilmu Komputer \\ STMIK Nusa Mandiri Jakarta \\ http://nusamandiri.ac.id/ \\ 1bayusugaraa@gmail.com,2agus@nusamandiri.ac.id \\ ${ }^{2}$ Pusat Penelitian Elektronika dan Telekomunikasi \\ Lembaga Ilmu Pengetahuan Indonesia (LIPI) \\ http://lipi.go.id/ \\ agus@subekti@lipi.go.id
}

\begin{abstract}
As time goes by the development of science and information technology, the presence of machine learning in the field of computers have become one of the trends and attracts a lot of attention. The application of machine learning is not regardless of using the data. The large data is often used in the learning process of machine learning. The development of machine learning grows so rapid that can enable the large data be accumulated so quickly. However, the machine learning is rarely found using the small data in the learning process. These small datasets are usually private that taken from the organization which would be the object of research such as the data on the banks, the hospitals, the factories and the service companies. In this research, the researcher exploit the Support Vector Machine of Algorithm and K-Fold Corss Validation to test the value of the accuracy of the small datasets and to utilize the ensemble techniques to determine how the ensemble technique affected the Support Vector Machine of Algorithm. The result of this research shows that the ensemble technique can improve the accuracy performance in Support Vector Machine. The SVM Algorithm model and the ensemble technique with poly kernel shows the best accuracy value of $91 \%$.
\end{abstract}

Keywords: Machine Learning, Support Vector Machine, Small Dataset, Poly kernel, Teknik Ensemble.

Intisari- Seiring dengan perkembangan ilmu pengetahuan dan teknologi informasi, kehadiran machine learning dibidang komputer telah menjadi salah satu tren dan menarik banyak perhatian. Penggunaan machine learning tidak terlepas dari penggunaan data dalam pembelajarannya. Data yang besar merupakan data yang sering digunakan dalam proses pembelajaran machine learning. Perkembangan machine learning yang sangat pesat dapat memungkinkan data yang besar cepat pula terakumulasi. Namun, jarang ditemukan machine learning menggunakan data yang kecil (small dataset) dalam proses pembelajarannya. Small dataset ini biasanya bersifat private yang diambil dari sebuah organisasi yang akan dijadikan objek penelitian seperti data bank, rumah sakit, pabrik dan perusahaan jasa. Dalam penelitian ini peneliti menggunakan algoritma Support Vector Machine dan $k$-fold corss validation untuk menguji nilai keakuratan small dataset serta menggunakan teknik ensemble untuk mengetahui seberapa pengaruhnya teknik ensemble terhadap algoritma Support Vector Machine. Hasil dari penelitian ini menunjukkan bahwa teknik ensemble dapat meningkatkan performa akurasi pada Support Vector Machine. Model algoritma Support Vector Machine dan teknik ensemble dengan poly kernel menunjukkan nilai akurasi terbaik yaitu sebesar $91 \%$.

Kata Kunci: Machine Learning, Support Vector Machine, Small Dataset, Poly kernel, Teknik Ensemble.

\section{PENDAHULUAN}

Tumbuh kembang anak merupakan hal yang sangat penting bagi orang tua (Permono, 2013). Dengan melakukan deteksi dini terhadap tumbuh kembang anak, orang tua diharapkan mampu mengetahui tumbuh kembang pada anaknya baik tumbuh kembang yang normal maupun adanya gangguan dalam tumbuh kembang anak. Salah satu gangguan tumbuh kembang yang dialami oleh anak adalah gangguan autis.

Autis merupakan gangguan perkembangan fungsi otak yang mencakup bidang sosial, komunikasi verbal (bahasa) dan non-verbal, 
imajinasi dan fleksibiltas, lingkup minat, kognisi dan perhatian (Gardenia, Tursina, \& Pratiwi, 2015). Anak autistik ditinjau dari masa kemunculannya atau kejadiannya dapat terjadi sejak lahir yang disebut dengan autistik klasik dan sesudah lahir dimana anak hingga umur 1-2 tahun menunjukkan perkembangannya yang normal (Siwi \& Anganti, 2017).

Autisme memiliki dampak yang nyata di sisi sosial dari penderita. Penderita penyakit ini seakan-akan hidup didunianya sendiri (Hendita, Kusuma, Si, Cs, \& Oktana, 2012). Dengan adanya hal ini, penyandang autis akan terisolir dengan dunia luar sehingga banyak orang tua yang malu dan kurang percaya diri dengan keadaan anaknya yang memiliki kekurangan sehingga banyak orang tua juga tidak bisa menerima keadaan yang dimiliki anaknya (Susanto, 2014). Penyandang autis juga memiliki keterbatasan dalam hal komunikasi sehingga menyebabkan mereka berbicara tidak dipakai untuk berkomunikasi dengan orang lain tetapi dengan dirinya sendiri (Boham, 2013).

Hal ini lah yang dianggap perlu untuk ditangani, berhubung 1 dari 600 anak di Indonesia menyandang penyakit autis, harus ada suatu cara untuk menyelesaikan permasalahan (Budiman, Santoso, \& Afirianto, 2017). Ini akan sangat bermanfaat bagi dokter, membantu mereka mendeteksi Autism Spectrum Disorder pada tahap yang jauh lebih produktif (Bekerom, 2012). Semakin cepat dokter dalam pengambilan keputusan, semakin cepat pula anak terkena autis dapat ditangani.

Dengan minimnya informasi autisme yang belum didapatkan oleh masyarakat luas khususnya orang tua, banyak yang tidak mengerti apa itu gangguan autisme (Merianto, 2016) dan bagaimana cara penanganannya. Para orang tua lebih memilih mencari seorang dokter/ahli tumbuh kembang anak untuk berkonsultasi (Sugara, Widyatmoko, Prakoso, 2018). Dengan ketersediaan dokter/ahli tumbuh kembang anak saat ini, serta jika menggunakan prosedur pendiagnosa secara lengkap membuat orang tua mengeluarkan biaya yang relatif besar serta waktu yang terbuang hanya untuk berkonsultasi.

Seiring dengan perkembangan ilmu pengetahuan dan teknologi informasi, kehadiran machine learning di bidang komputer telah menarik banyak perhatian. Machine learning menjadi sebuah tren dalam teknologi informasi. Saat ini perkembangan teknologi informasi telah merambah ke berbagai sektor termasuk kesehatan (Munawarah, Soesanto, \& Faisal, 2016). Machine learning yang digunakan pada bidang kesehatan bertujuan untuk memprediksi sebuah penyakit. Dengan hasil prediksi yang lebih cepat diterima oleh dokter/pakar kesehatan, semakin cepat pula tindakan atau penangannya terhadap sebuah penyakit.

Penggunaan machine learning tidak lepas dari penggunaan data itu sendiri. Machine learning memainkan peran yang luas dalam pengembangan terutama dalam pengembangan data analitik (Alarifi \& Young, 2018). Data yang besar merupakan data yang sering digunakan dalam proses pembelajaran machine learning itu sendiri. Perkembangan machine learning yang sangat pesat dapat memungkinkan data yang besar cepat pula terakumulasi. Namun, jarang ditemukan machine learning menggunakan data yang kecil (small dataset) dalam proses pembelajarannya. Small dataset ini biasanya bersifat private yang diambil dari sebuah organisasi yang akan dijadikan objek penelitian seperti data bank, rumah sakit, pabrik dan perusahaan jasa.

Penelitian dengan small dataset pernah dilakukan oleh (Shaikhina et al., 2015), Dataset eksperimental dalam bioteknologi umumnya terbatas dalam ukuran, sehingga membuat Machine Learning (ML) tidak praktis untuk pemodelan prediktif. Teknik-teknik baru dari multiple run untuk pengembangan model dan analisis data pengganti untuk validasi model disarankan untuk prediksi hasil biomedis berdasarkan pada dataset kecil untuk tugas klasifikasi dan regresi. Kerangka yang diusulkan diaplikasikan untuk merancang model Neural Network untuk stratifikasi risiko fraktur tulang osteoarthritic, dan model Decision Tree untuk prediksi penolakan transplantasi ginjal yang dimediasi oleh antibodi. Meskipun set data kecil (35 spesimen tulang dan 80 transplantasi ginjal), kedua model mencapai akurasi tinggi masingmasing 98,3\% dan $85 \%$.

Penelitian selanjutnya dengan menggunakan small dataset telah dilakukan oleh (Sharma \& Sharma, 2016), Klasifikasi adalah teknik pembelajaran yang dilindungi yang penting yang digunakan oleh banyak aplikasi. Faktor penting pada dimana kinerja dari sebuah classifier tergantung adalah ukuran dataset yang akan digunakan oleh classifier untuk dilatih. Di naskah ini penulis telah menganalisis lima berbeda teknik klasifikasi (yaitu pohon keputusan, KNN, SVM, linear diskriminan dan metode Ensemble) dalam hal AUC dan akurasi prediksi ketika dilatih menggunakan dataset kecil dengan dimensi yang berbeda. Penelitian telah dilakukan menggunakan dataset dengan 24 fitur dan 400 instance (sampel). Hasilnya menunjukkan bahwa, secara umum metode ensemble (menggunakan meningkatkan pohon) berkinerja lebih baik daripada yang lain tetapi kinerja sedikit terdegradasi dengan dimensi berkurang. 
Sedangkan penelitian yang dilakukan oleh (Feng, Zhou, \& Dong, 2019) menggunakan small dataset untuk memprediksi cacat pemadatan oleh regresi DNN dengan dataset kecil yang berisi 487 titik data. Itu ditemukan bahwa DNN pra-terlatih dan fine-tuned menunjukkan kinerja generalisasi yang lebih baik melalui jaringan saraf dangkal, mendukung mesin vektor, dan DNN dilatih oleh metode konvensional. DNN terlatih mengubah eksperimen yang tersebar data menunjuk ke peta akurasi tinggi dalam kimia dimensi tinggi dan parameter pemrosesan ruang. Meskipun DNN dengan dataset besar adalah solusi optimal, DNN dengan dataset kecil dan pra-pelatihan bisa pilihan yang masuk akal ketika dataset besar tidak tersedia dalam studi materi.

Berdasarkan uraian tersebut diatas, penelitian deteksi dini gangguan autisme ini akan menggunakan small dataset dengan salah satu algoritma machine learning yaitu dengan algorima support vector machine yang bertujuan untuk memperoleh nilai akurat melalui permodelan machine learning dalam deteksi dini gannguan autisme. Penelitian deteksi dini gangguan autisme ini juga menggunakan teknik ensemble yang akan diuji terhadap algoritma support vector machine untuk dapat menjawab pertanyaan sebagai berikut:

1. Bagaimana efektifitas penerapan algoritma support vector machine dengan menggunakan small dataset?

2. Bagaimana nilai akurasi yang dihasilkan dari penerapan algoritma support vector machine dengan menggunakan small dataset?

3. Bagaimana pengaruh teknik ensemble pada pengujian algoritma support vector machine dengan menggunakan small dataset?

\section{BAHAN DAN METODE}

\section{A. Algoritma Support Vector Machine}

Pengertian Support Vector Machine (SVM) yaitu sistem pembelajaran yang menggunakan ruang hipotesis berupa fungsi - fungsi linier dalam sebuah fitur yang berdimensi tinggi dan dilatih dengan menggunakan algoritma pembelajaran yang didasarkan pada teori optimasi (Puspitasari, Ratnawati, \& Widodo, 2018). Support Vector Machine (SVM) diperkenalkan oleh Vapnik, Boser dan Guyon pada tahun 1992 (Fridayanthie, 2015) sebagai rangkaian dari beberapa konsep-konsep unggulan dalam bidang pattern recognition (Susilowati, Sabariah, \& Gozali, 2015).

Tingkat akurasi pada model yang akan dihasilkan oleh proses peralihan dengan SVM sangat bergantung terhadap fungsi kernel dan parameter yang digunakan (Parapat \& Furqon, 2018). Berdasarkan dari karakteristiknya, metode
SVM dibagi menjadi dua, yaitu SVM Linier dan SVM Non-Linier. SVM linier merupakan data yang dipisahkan secara linier, yaitu memisahkan kedua class pada hyperplane dengan soft margin. Sedangkan SVM Non-Linier yaitu menerapkan fungsi dari kernel trick terhadap ruang berdimensi tinggi (Rachman \& Purnami, 2012).

Pada dokumentasi Matlab, SVM untuk prediksi disebut dengan SVM Regression terdiri dari fungsi linear dan nonlinear dengan primal formula dan dual formula) (Nurmasani, Utami, \& Al Fatta, 2017). Metode SVM Regression disebut sebagai suatu teknik nonparametric karena bergantung pada fungsi kernel. Beberapa tipe kernel yang digunakan dapat dijabarkan pada tabel 1 berikut:

Tabel 1. Tipe Kernel

\begin{tabular}{lc}
\hline \multicolumn{1}{c}{ Nama Kernel } & Fungsi Kernel \\
\hline Linear (dot) & $G\left(x_{1}, x_{2}\right)=x_{1}{ }^{\prime} x_{2}$ \\
\hline RBF & $G\left(x_{1}, x_{2}\right)=\exp$ \\
\hline Polynomial & $G\left(x_{1}, x_{2}\right)=$ \\
\hline Sumber: (Nurmasani
\end{tabular}

Sumber: (Nurmasani et al., 2017)

Matriks Gram adalah matriks n x $\mathrm{n}$ yang mengandung unsur $g i, j=\mathrm{G}(\mathrm{x}, \mathrm{z})$. Setiap elemen $g i, j$ sama dengan nilai awal dari suatu prediktor dengan nilai peubah $\varphi$. Namun, tidak perlu mengetahui nilai $\varphi$, karena dapat menggunakan fungsi kernel untuk menghasilkan matriks Gram secara langsung. Dengan menggunakan metode ini, SVM nonlinier menemukan fungsi optimal $\mathrm{f}(\mathrm{x})$ dalam perubahan ruang prediktor.

Rumus ganda untuk SVM regresi nonlinear menggantikan nilai awal prediktor $\mathrm{X}^{\wedge} \mathrm{T} \mathrm{Z}$ dengan elemen yang sesuai dari matriks Gram $(g i, j)$. SVM regresi nonlinier menemukan koefisien yang meminimalkan seperti pada persamaan 1 :

$$
\begin{aligned}
& L(a)=\frac{1}{2} \sum_{i=1}^{N} \sum_{j=1}^{N}\left(\alpha_{i}-\alpha_{j}\right)\left(\alpha_{j}-\alpha_{j}\right) G\left(x_{i}, x_{j}\right)+ \\
& \varepsilon \sum_{i=1}^{N}\left(\alpha_{i}+\alpha_{i}\right)-\sum_{i=1}^{N} y_{i}\left(\alpha_{i}+\alpha_{i}\right) \ldots \ldots \ldots \ldots \ldots
\end{aligned}
$$

Dimana:

$\sum_{n=1}^{N}\left(\propto_{n}-\propto_{n}\right)=0$

$\forall s n: 0 \leq \alpha_{n} \leq C$

$\forall n: 0 \leq \alpha_{n} \leq C(4)$

Kondisi Karush-Kuhn-Tucker (KKT) harus memenuhi kondisi sebagai berikut:

$$
\begin{aligned}
& \forall n: \alpha_{n}\left(\varepsilon+\xi_{n}-y_{n}+f\left(x_{n}\right)\right)=0 \\
& \forall n: \alpha_{n}\left(\varepsilon+\xi_{n}+y_{n}-f\left(x_{n}\right)\right)=0
\end{aligned}
$$


$\forall n: \xi_{n}\left(C-\alpha_{n}\right)=0$

$\forall n: \xi_{n}\left(C-\alpha_{n}\right)=0$

Kondisi tersebut menunjukkan bahwa epsilon memiliki fungsi pengganda Lagrange $\alpha_{n}=0$ dan $\alpha_{n}=0$. Pengganda Lagrange bukan nol disebut dukungan vector atau support vector. Fungsi yang digunakan untuk memprediksi nilai baru pada support vector seperti persamaan 9 berikut:

$f(x)=\sum_{n=1}^{N}\left(\alpha_{n}-\alpha_{n}\right) G\left(x_{n}, x\right)+b$

\section{B. Teknik Pengumpulan Data}

Data yang digunakan dalam penelitian deteksi dini gangguan autisme ini merupakan data primer yang diperoleh dari hasil wawancara disebuah lembaga Autisme di Bekasi Jawa Barat, selain wawancaran, data penelitian ini juga diperoleh dari hasil sebaran kuesioner online yang dapat diakses dengan menggunakan url https://forms.gle/YSvYcnRxi21dLzfP9.

Data yang diperoleh terdiri dari 2 parameter yaitu data gejala autisme yang digunakan sebagai atribut pada penelitian ini sedangkan data gangguan autisme digunakan sebagai class yang dijelaskan sebagai berikut:

Tabel 2. Data Gangguan Autisme Kode Gangguan Nama Gangguan

\begin{tabular}{ll}
\hline GG01 & Gangguan Perilaku \\
\hline GG02 & Gangguan Komunikasi
\end{tabular}

Sumber: (Sugara \& Subekti, 2019)

Sedangkan yang data primer yang dijadikan sebagai atribut pada penelitian deteksi dini gangguan autisme ini dapat dijelaskan sebagai berikut:

Tabel 3. Data Gejala Autisme

\begin{tabular}{cl}
\hline $\begin{array}{c}\text { Kode } \\
\text { Gejala }\end{array}$ & \multicolumn{1}{c}{ Nama Gejala } \\
\hline GJ01 & Tidak memiliki kontak mata \\
\hline GJ02 & Suka diam/menyendiri \\
\hline GJ03 & Tidak suka dipeluk \\
\hline GJ04 & Tidak dapat merespon jika dipanggil orang \\
\hline GJ05 & $\begin{array}{l}\text { Suka melakukan kegiatan/gerakan secara } \\
\text { berulang-ulang }\end{array}$ \\
\hline GJ06 & Suka terpaku terhadap benda-benda tertentu \\
\hline GJ07 & $\begin{array}{l}\text { Suka menyukai hal yang aneh seperti } \\
\text { mencium-cium benda }\end{array}$ \\
\hline GJ08 & $\begin{array}{l}\text { Suka mengungkapkan emosi (sedih, senang, } \\
\text { marah dll) dengan sendirinya tanpa sebab }\end{array}$ \\
\hline GJ09 & Tidak bisa diam \\
\hline GJ10 & Tidak dapat berbicara \\
\hline GJ11 & Bisa berbicara namun tidak jelas \\
\hline GJ12 & Sering berbicara berlebihan \\
\hline GJ13 & $\begin{array}{l}\text { Suka mengucapkan bahasa/kata-kata yang } \\
\text { aneh secara berulang-ulang }\end{array}$ \\
\hline GJ14 & Tidak dapat menunjuk sesuatu dengan jari \\
\hline
\end{tabular}

\begin{tabular}{cl}
\hline $\begin{array}{c}\text { Kode } \\
\text { Gejala }\end{array}$ & \multicolumn{1}{c}{ Nama Gejala } \\
\hline \multicolumn{3}{c}{ sendiri } \\
\hline GJ15 & $\begin{array}{l}\text { Tidak dapat menunjukkan keinginan dengan } \\
\text { kata-kata }\end{array}$ \\
\hline GJ16 & $\begin{array}{l}\text { Suka menarik-narik orang lain jika } \\
\text { menginginkan sesuatu }\end{array}$ \\
\hline GJ17 & Tidak ada usaha dalam berkomunikasi \\
\hline GJ18 & Menghindar jika didekati \\
\hline GJ19 & $\begin{array}{l}\text { Tidak dapat berinteraksi dengan lingkungan } \\
\text { sekitar }\end{array}$ \\
\hline GJ20 & Tidak tertarik dengan orang lain \\
\hline GJ21 & Tidak peduli dengan sekitarnya \\
\hline GJ22 & Tidak suka dengan keramaian \\
\hline GJ23 & Tidak suka bermain dengan teman sebayanya \\
\hline GJ24 & Tidak dapat bersosialisasi dengan orang lain \\
\hline Sumber: (Sugara \& Subekti, 2019)
\end{tabular}

\section{HASIL DAN PEMBAHASAN}

Pengujian deteksi dini gangguan autisme ini menggunakan 67 dataset yang diperoleh dari hasil wawancara dan sebaran kuesioner. Data set yang akan duji pada penelitian ini adalah sebagai berikut:

Tabel 4. Dataset Gangguan Autisme

\begin{tabular}{|c|c|c|c|c|c|}
\hline & $\begin{array}{c}\text { Anak } \\
\text { Ke-1 }\end{array}$ & $\begin{array}{c}\text { Anak } \\
\text { Ke-2 }\end{array}$ & $\begin{array}{c}\text { Anak } \\
\text { Ke-3 }\end{array}$ & $\begin{array}{c}\text { Anak } \\
\text { Ke-4 }\end{array}$ & $\begin{array}{c}\text { Anak } \\
\text { Ke-5 }\end{array}$ \\
\hline GJ01 & Tidak & $\mathrm{Ya}$ & Tidak & Tidak & Tidak \\
\hline GJ02 & $\mathrm{Ya}$ & Tidak & $\mathrm{Ya}$ & $\mathrm{Ya}$ & $\mathrm{Ya}$ \\
\hline GJ03 & Tidak & Tidak & Tidak & $\mathrm{Ya}$ & $\mathrm{Ya}$ \\
\hline GJ04 & Tidak & $\mathrm{Ya}$ & Tidak & Tidak & Tidak \\
\hline GJ05 & $\mathrm{Ya}$ & $\mathrm{Ya}$ & Tidak & $\mathrm{Ya}$ & $\mathrm{Ya}$ \\
\hline GJ06 & $\mathrm{Ya}$ & Tidak & $\mathrm{Ya}$ & $\mathrm{Ya}$ & Tidak \\
\hline GJ07 & $\mathrm{Ya}$ & Tidak & $\mathrm{Ya}$ & Tidak & $\mathrm{Ya}$ \\
\hline GJ08 & Tidak & Tidak & Ya & $\mathrm{Ya}$ & $\mathrm{Ya}$ \\
\hline GJ09 & Tidak & $\mathrm{Ya}$ & $\mathrm{Ya}$ & Tidak & Tidak \\
\hline GJ10 & Tidak & $\mathrm{Ya}$ & Tidak & Tidak & Tidak \\
\hline GJ11 & $\mathrm{Ya}$ & Tidak & $\mathrm{Ya}$ & Tidak & $\mathrm{Ya}$ \\
\hline GJ12 & $\mathrm{Ya}$ & Tidak & Tidak & $\mathrm{Ya}$ & $\mathrm{Ya}$ \\
\hline GJ13 & Ya & Tidak & Ya & Ya & Tidak \\
\hline GJ14 & Tidak & $\mathrm{Ya}$ & Tidak & Tidak & $\mathrm{Ya}$ \\
\hline GJ15 & Tidak & $\mathrm{Ya}$ & $\mathrm{Ya}$ & Tidak & Tidak \\
\hline GJ16 & $\mathrm{Ya}$ & Tidak & Tidak & Tidak & Tidak \\
\hline GJ17 & Tidak & Ya & Ya & Tidak & Ya \\
\hline GJ18 & Tidak & Tidak & Tidak & Tidak & Tidak \\
\hline GJ19 & Ya & Ya & Ya & Ya & Ya \\
\hline GJ20 & $\mathrm{Ya}$ & $\mathrm{Ya}$ & $\mathrm{Ya}$ & $\mathrm{Ya}$ & Tidak \\
\hline GJ21 & $\mathrm{Ya}$ & $\mathrm{Ya}$ & $\mathrm{Ya}$ & $\mathrm{Ya}$ & $\mathrm{Ya}$ \\
\hline GJ22 & $\mathrm{Ya}$ & Tidak & Tidak & Ya & Ya \\
\hline GJ23 & $\mathrm{Ya}$ & $\mathrm{Ya}$ & Tidak & $\mathrm{Ya}$ & Ya \\
\hline GJ24 & Ya & $\mathrm{Ya}$ & Ya & $\mathrm{Ya}$ & $\mathrm{Ya}$ \\
\hline Hasil & GG03 & GG02 & GG01 & GG03 & GG03 \\
\hline
\end{tabular}

Sumber: (Sugara \& Subekti, 2019)

Penelitian deteksi dini gangguan autisme ini menggunakan model algoritma Support Vector Machine (SVM) dengan menggunakan pengujian $k$ fold cross validation. Dalam penelitian ini digunakan beberapa kernel SVM yang digunakan untuk menentukan akurasi terbaik diantaranya adalah normalized poly kernel, poly kernel dan RBF kernel. Diuji kembali dengan menggunakan teknik ensemble yang terdiri dari AdaBoost dan Bagging 
untuk menentukan nilai akurasi terbaik. Hasil dari pengujian kernel SVM dapat dijelaskan sebagai berikut:

\section{A. Hasil Pengujian Algoritma SVM}

Dari pengujian algoritma SVM dengan menggunakan beberapa teknik kernel dapat dihasilkan sebagai berikut:

Tabel 5. Pengujian SVM

\begin{tabular}{lccc}
\hline & $\begin{array}{c}\text { Poly } \\
\text { Kernel }\end{array}$ & $\begin{array}{c}\text { Normalized } \\
\text { Poly Kernel }\end{array}$ & $\begin{array}{c}\text { RBF } \\
\text { Kernel }\end{array}$ \\
\hline Akurasi & 83.58 & 85.07 & 56.71 \\
\hline TP Rate & 0.836 & 0.851 & 0.567 \\
\hline FP Rate & 0.123 & 0.165 & 0.567 \\
\hline Precision & 0.832 & 0.854 & 0 \\
\hline Recall & 0.836 & 0.851 & 0.567 \\
\hline F-Measure & 0.834 & 0.829 & 0 \\
\hline MCC & 0.717 & 0.745 & 0 \\
\hline ROC Area & 0.894 & 0.861 & 0.501 \\
\hline PRC Area & 0.796 & 0.77 & 0.417 \\
\hline
\end{tabular}

Sumber: (Sugara \& Subekti, 2019)

Dari Tabel 5. Pengujian SVM diatas dapat dijelaskan bahwa Normalized Poly Kernel memiliki nilai akurasi terbaik sebesar $85.07 \%$ dengan TP Rate sebesar 0.851 dan FP Rate sebesar 0.165.

\section{B. Hasil Pengujian Algoritma SVM + Teknik Ensemble AdaBoost}

Selanjutnya pengujian dengan menggunakan SVM dan salah satu teknik ensemble yaitu AdaBoost. Hasil pengujiannya sebagai berikut:

Tabel 6. Pengujian SVM + Teknik Ensemble Adaboost

\begin{tabular}{lccc}
\hline & $\begin{array}{c}\text { Poly } \\
\text { Kernel }\end{array}$ & $\begin{array}{c}\text { Normalized } \\
\text { Poly Kernel }\end{array}$ & $\begin{array}{c}\text { RBF } \\
\text { Kernel }\end{array}$ \\
\hline Akurasi & 85.07 & 79.1 & 56.71 \\
\hline TP Rate & 0.851 & 0.791 & 0.567 \\
\hline FP Rate & 0.119 & 0.151 & 0.567 \\
\hline Precision & 0.849 & 0.782 & 0 \\
\hline Recall & 0.851 & 0.791 & 0.567 \\
\hline F- & 0.849 & 0.785 & 0 \\
Measure & & & \\
\hline MCC & 0.744 & 0.641 & 0 \\
\hline ROC Area & 0.912 & 0.939 & 0.501 \\
\hline PRC Area & 0.853 & 0.903 & 0.417 \\
\hline
\end{tabular}

Sumber: (Sugara \& Subekti, 2019)

Dari Tabel 6. Pengujian SVM dengan salah satu teknik ensemble yaitu AdaBoost diatas dapat dijelaskan bahwa Poly Kernel memiliki nilai akurasi terbaik sebesar $85.07 \%$ dengan TP Rate sebesar 0.851 dan FP Rate sebesar 0.119. Teknik Esemble AdaBoost ini menunjukkan dapat meningkatkan nilai akurasi terhadap perhitungan SVM menggunakan poly kernel.

\section{Hasil Pengujian Algoritma SVM + Teknik Ensemble Bagging}

Pengujian selanjutnya dengan menggunakan SVM dan salah satu teknik ensemble yaitu Bagging. Hasil pengujiannya sebagai berikut:

Tabel 7. Pengujian SVM + Teknik Ensemble

\begin{tabular}{lccc}
\multicolumn{4}{c}{ Bagging } \\
& $\begin{array}{c}\text { Poly } \\
\text { Kernel }\end{array}$ & $\begin{array}{c}\text { Normalized Poly } \\
\text { Kernel }\end{array}$ & $\begin{array}{c}\text { RBF } \\
\text { Kernel }\end{array}$ \\
\hline Akurasi & 91.04 & 82.08 & 56.71 \\
\hline TP Rate & 0.91 & 0.821 & 0.567 \\
\hline FP Rate & 0.087 & 0.204 & 0.567 \\
\hline Precision & 0.91 & 0.832 & 0 \\
\hline Recall & 0.91 & 0.821 & 0.567 \\
\hline F-Measure & 0.908 & 0.8 & 0 \\
\hline MCC & 0.845 & 0.695 & 0 \\
\hline ROC Area & 0.954 & 0.903 & 0.593 \\
\hline PRC Area & 0.927 & 0.834 & 0.491 \\
\hline Sumber: & &
\end{tabular}

Sumber: (Sugara \& Subekti, 2019)

Dari Tabel 7. Pengujian SVM dengan salah satu teknik ensemble yaitu Bagging. Sama seperti teknik ensemble AdaBoost, Poly Kernel memiliki nilai akurasi terbaik sebesar $91.04 \%$ dengan TP Rate sebesar 0.91 dan FP Rate sebesar 0.087. Teknik Esemble Bagging ini juga menunjukkan dapat meningkatkan nilai akurasi terhadap perhitungan SVM menggunakan poly kernel.

\section{KESIMPULAN}

Pengujian pada penelitian deteksi dini gangguan autisme ini mengusulkan algoritma support vector machine (SVM) untuk memberikan nilai akurasi yang terbaik dengan menggunakan small dataset. Dataset yang dipakai pada pengujian ini sebanyak 67 dengan menghasilkan nilai akurasi yang tertinggi sebesar $85 \%$ pada normalized poly kernel. Dua teknik ensemble yaitu AdaBoost dan Bagging juga diusulkan dalam pengujian penelitian deteksi dini gangguan autisme ini untuk meningkatkan kinerja klasifikasi algoritma support vector machine (SVM). Berdasarkan hasil eksperimen yang telah dilakukan menunjukkan bahwa teknik ensemble menunjukkan performa dapat meningkatkan nilai akurasi. Model SVM dengan poly kernel dan teknik ensemble Bagging menunjukkan nilai akurasi tertinggi yaitu sebesar $91 \%$.

\section{REFERENS}

Alarifi, H. S., \& Young, G. S. (2018). Using Multiple Machine Learning Algorithms to Predict Autism in Children. International Conference Artificial Intteligence, 464-467.

Bekerom, B. Van Den. (2012). Using Machine Learning for Detection of Autism Spectrum Disorder.

Boham, S. E. (2013). Pola Komunikasi Orang Tua 
Dengan Anak Autis (Studi pada orang tua dari anak autis di Sekolah Luar Biasa AGCA Center Pumorow Kelurahan Banjer Manado). Journal, II(4).

Budiman, E., Santoso, E., \& Afirianto, T. (2017). Pendeteksi Jenis Autis pada Anak Usia Dini Menggunakan Metode Linear Discriminant Analysis ( LDA ). Jurnal Pengembangan Teknologi Informasi Dan Ilmu Komputer, 1(August), 583-592.

Feng, S., Zhou, H., \& Dong, H. (2019). Using deep neural network with small dataset to predict material defects. Materials and Design, 162, 300-310.

https://doi.org/10.1016/j.matdes.2018.11.0 60

Fridayanthie, E. W. (2015). Analisa Data Mining Untuk Prediksi Penyakit Hepatitis Dengan Menggunakan Metode Naive Bayes dan Support Vector Machine. Jurnal Khatulistiwa Informatika, 3, 24-36.

Gardenia, M., Tursina, \& Pratiwi, H. S. (2015). Sistem Pakar Deteksi Autisme Pada Anak Menggunakan Metode Fuzzy Tsukamoto. Jurnal Sistem Dan Teknologi Informasi, 2(1), 1-6.

Hendita, G., Kusuma, A., Si, S., Cs, M., \& Oktana, L. (2012). Sistem Identifikasi Penyakit Autis Anak Berbasis Web. Jurnal TICOM, 1(1), 2941.

Merianto, R. W. (2016). Peran Orang Tua Dalam Menangani Anak Autis. Jom Fisip, 3(1), 1-15.

Munawarah, R., Soesanto, O., \& Faisal, M. R. (2016). Penerapan Metode Support Vector Machine, 04(01), 103-113.

Nurmasani, A., Utami, E., \& Al Fatta, H. (2017). Analisis Support Vector Machine. Jurnal Informasi Interaktif, 2(1).

Parapat, I. M., \& Furqon, M. T. (2018). Penerapan Metode Support Vector Machine ( SVM ) Pada Klasifikasi Penyimpangan Tumbuh Kembang Anak. Jurnal Pengembangan Teknologi Informasi Dan Ilmu Komputer (JPTIIK) Universitas Brawijaya, 2(10), 31633169.

Permono, H. (2013). Peran Orang Tua dalam Optimalisasi Tumbuh Kembang Anak untuk Membangun Karakter Anak Usia Dini. Prosiding Seminar Nasional Parenting, 3447.
Puspitasari, A. M., Ratnawati, D. E., \& Widodo, A. W. (2018). Klasifikasi Penyakit Gigi Dan Mulut Menggunakan Metode Support Vector Machine. Jurnal Pengembangan Teknologi Informasi Dan Ilmu Komputer, 2(2), 802-810.

Rachman, F., \& Purnami, W. S. (2012). Perbandingan Klasifikasi Tingkat Keganasan Breast Cancer Dengan Menggunakan Regresi Logistik Ordinal Dan Support Vector Machine (SVM). Jurnal Sains Dan Seni ITS, 1(1). https://doi.org/10.12962/j23373520.v1i1.1 932

Shaikhina, T., Lowe, D., Daga, S., Briggs, D., Higgins, R., \& Khovanova, N. (2015). Machine learning for predictive modelling based on small data in biomedical engineering. IFACPapersOnLine, 28(20), 469-474. https://doi.org/10.1016/j.ifacol.2015.10.18 5

Sharma, S., \& Sharma, V. (2016). Performance of Various Machine Learning Classifiers on Small Datasets with Varying Dimensionalities: A Study. Circulation in Computer Science, 1(1), 30-35. https://doi.org/10.22632/ccs-2016-251-23

Siwi, A. R. K., \& Anganti, N. R. N. (2017). Strategi Pengajaran Interaksi Sosial pada Anak Autis. Indigenous: Jurnal Ilmiah Psikologi, 2(2), 184-192.

https://doi.org/10.23917/indigenous.v2i2.5 703

Sugara, Widyatmoko, Prakoso, S. D. (2018). Penerapan Algoritma C4.5 untuk Deteksi Dini Gangguan Autisme Pada Anak. Seminar Nasional Teknologi Informasi Dan Komunikasi (SENTIKA), 87-96.

Sugara, B., \& Subekti, A. (2019). Penerapan Support Vector Machine (SVM) Pada Small Dataset Untuk Deteksi Dini Gangguan Autisme. Laporan Akhir.

Susanto, S. E. (2014). Penerimaan Orang tua terhadap Kondisi Anaknya yang Menyandang Autisme di Rumah Terapis Little Star. Jurnal Psikosains, 9(2), 140-152.

Susilowati, E., Sabariah, M. K., \& Gozali, A. A. (2015). Implementasi Metode Support Vector Machine untuk Melakukan Klasifikasi Kemacetan Lalu Lintas Pada Twitter. EProceeding of Engineering, 2(1), 1-7. 